\title{
Virulence of Pseudomonas syringae pv. tomato DC3000 Is Influenced by the Catabolite Repression Control Protein Crc
}

\author{
Suma Chakravarthy, ${ }^{1}$ Bronwyn G. Butcher, ${ }^{1}$ Yingyu Liu, ${ }^{1}$ Katherine D'Amico,,${ }^{1,2}$ Matthew Coster, ${ }^{1}$ and \\ Melanie J. Filiatrault ${ }^{1,2}$ \\ ${ }^{1}$ School of Integrative Plant Science, Section of Plant Pathology and Plant-Microbe Biology, Cornell University, Ithaca, NY \\ 14853, U.S.A.; and ${ }^{2}$ Emerging Pests \& Pathogens Research Unit, Robert W. Holley Center for Agriculture and Health, \\ Agricultural Research Service, United States Department of Agriculture, Ithaca, NY 14853, U.S.A.
}

Accepted 2 February 2017.

\begin{abstract}
Pseudomonas syringae infects diverse plant species and is widely used as a model system in the study of effector function and the molecular basis of plant diseases. Although the relationship between bacterial metabolism, nutrient acquisition, and virulence has attracted increasing attention in bacterial pathology, it is largely unexplored in $P$. syringae. The Crc (catabolite repression control) protein is a putative RNAbinding protein that regulates carbon metabolism as well as a number of other factors in the pseudomonads. Here, we show that deletion of $\operatorname{crc}$ increased bacterial swarming motility and biofilm formation. The $\operatorname{crc}$ mutant showed reduced growth and symptoms in Arabidopsis and tomato when compared with the wild-type strain. We have evidence that the $\operatorname{crc}$ mutant shows delayed hypersensitive response (HR) when infiltrated into Nicotiana benthamiana and tobacco. Interestingly, the crc mutant was more susceptible to hydrogen peroxide, suggesting that, in planta, the mutant may be sensitive to reactive oxygen species generated during pathogen-associated molecular pattern-triggered immunity (PTI). Indeed, HR was further delayed when PTI-induced tissues were challenged with the $c r c$ mutant. The $\operatorname{crc}$ mutant did not elicit an altered PTI response in plants compared with the wild-type strain. We conclude that Cre plays an important role in growth and survival during infection.
\end{abstract}

The plant pathogen strain Pseudomonas syringe pv. tomato DC3000 is the causal agent of bacterial speck on tomato (Cuppels 1986; Preston 2000) and has been studied extensively

Current address for S. Chakravarthy: USDA-APHIS, Riverdale, MD 20737, U.S.A.

Current address for B. G. Burcher: Cornell Lab of Ornithology, Cornell University, 159 Sapsucker Woods Rd, Ithaca, NY 14850, U.S.A.

Current address for K. D'Amico: The Ohio State University, Center for Applied Plant Sciences, 1060 Carmack Road, Columbus, OH 43201, U.S.A.

Corresponding author: M. J. Filiatrault:

E-mail: Melanie.filiatrault@ars.usda.gov

*The $\boldsymbol{e}$-Xtra logo stands for "electronic extra" and indicates that four supplementary figures and one supplementary table are published online.

This article is in the public domain and not copyrightable. It may be freely reprinted with customary crediting of the source. The American Phytopathological Society, 2017. as a model organism, with many efforts aimed at teasing apart the molecular mechanisms involved in pathogenesis and in overcoming plant defense responses (Xin and He 2013). The pathogen $P$. syringae is equipped with a number of virulence factors (Ichinose et al. 2013). Some factors shown to be important in plant-pathogen interactions include flagella, phytotoxins such as coronatine, and extracellular polysaccharides. Flagella are important for plant colonization, invasion of the leaf apoplast, and bacterial entry through stomata (Nogales et al. 2015), as well as for the formation of cell aggregates called biofilms. P. syringae also produces several exopolysaccharides (EPSs), including alginate, levan, cellulose, and Psl (Arrebola et al. 2015; Laue et al. 2006; Records and Gross 2010; Yu et al. 1999). Many of these compounds have been shown to play a role in the attachment of bacterial cells to a surface (Laue et al. 2006) and formation or maintenance of biofilms (Laue et al. 2006) as well as pathogenesis of P. syringae (Arrebola et al. 2015; Yu et al. 1999).

Much attention has been given to the type III secretion system (T3SS) that deploys effector molecules into plant cells. This system significantly contributes to the ability of the pathogen to multiply and suppress the plant's basal defense responses or pathogen-associated molecular pattern (PAMP)triggered immunity (PTI) (Alfano and Collmer 2004) and, most often, results in disease development in a compatible host. However, in an incompatible interaction with a nonhost, such as the interaction of P. syringae pv. tomato DC3000 with Nicotiana benthamiana, recognition of one or several T3SS effectors by appropriate resistance proteins results in the elicitation of a hypersensitive response (HR) that tends to restrict bacterial multiplication (Lamb and Dixon 1997). A considerable amount of effort has been given to the study of these interactions and the molecular events underlying disease resistance mechanisms.

P. syringe pv. tomato DC3000 is considered a hemibiotrophic pathogen capable of causing disease in tomato as well as Arabidopsis. When conditions are optimal, usually when it is wet and cool, the bacteria invade the plant via wounds or natural openings like stomata. Once inside the plant host, the bacterium resides in the apoplastic space, where it must obtain nutrients from the host in order to multiply and survive. An indepth study of nutrient utilization by $P$. syringae (Rico and Preston 2008) showed that the sugars fructose, glucose, malate, and malonate, the organic acids citrate and succinate, and the amino acids $\gamma$-aminobutyric acid (GABA), aspartate, glutamate, glutamine, and serine are abundant in apoplastic extracts. 
DC3000 expresses pathways involved in the utilization of these molecules and, interestingly, appears to lack those pathways for assimilation of amino acids that are present in lower concentrations in the plant apoplast (Rico and Preston 2008). This lead to the hypothesis that $P$. syringe is specially adapted for growth in this particular environment. However, it is still not clear what nutrients are actually utilized by $P$. syringae during growth in plant tissue (Rico and Preston 2008).

The Crc protein is a catabolite repression control protein involved in regulating carbon metabolism in the Pseudomonas species (Morales et al. 2004; Rojo 2010). This system regulates the selection of preferred carbon sources by inhibiting the expression of the assimilation pathways for nonpreferred substrates when more desirable substrates are available. This optimization of bacterial metabolism allows for improved growth and ability of bacteria to thrive in the various settings they encounter (Görke and Stülke 2008; Poncet et al. 2009; Rojo 2010). Growth in poor carbon sources leads to activation of the $\mathrm{CbrA} / \mathrm{CbrB}$ two-component system, although the signal that activates $\mathrm{CbrA} / \mathrm{CbrB}$ is not known. The activation of this two-component system, along with the sigma factor RpoN, induces transcription of the small RNAs $\operatorname{crc} Z$ and $c r c X$ in P. syringae DC3000 (Filiatrault et al. 2013), crcZ and $c r c Y$ in P. putida (Moreno et al. 2012), and crcZ in P. aeruginosa (Sonnleitner et al. 2009). These small RNAs are able bind to $\mathrm{Crc}$ and relieve the Crc-mediated repression of mRNA targets, including genes encoding proteins involved in carbon utilization. Several models have been proposed to describe the molecular mechanism by which Crc inhibits translation of target mRNAs. Crc was initially thought to bind mRNAs directly at an AAnAAnAA motif (CA motif) near the translation start site and inhibit translation, but this idea was recently challenged (Milojevic et al. 2013). One model proposes that $c r c Z$ RNA binds to and sequesters the global RNA chaperone Hfq, which, in turn, relieves Hfq-mediated translational repression of mRNAs (Sonnleitner and Bläsi 2014). Another model proposes that $\mathrm{Crc}$ and $\mathrm{Hfq}$ cooperate in catabolite repression (Moreno et al. 2015). Further studies will help clarify the molecular mechanisms involved in catabolite repression in the pseudomonads.

Besides modulating catabolite repression and carbon metabolism, Crc has been shown to be involved in the regulation of several other factors, some of which are important for virulence. In $P$. aeruginosa, inactivation of the $\operatorname{crc}$ gene impairs swimming, swarming, and twitching motilities and increases EPS production and biofilm formation (Linares et al. 2010; O'Toole et al. 2000). Crc mutants also exhibit reduced virulence to Dictyostelium discoideum and reduced expression of quorum sensing-regulated virulence determinants, such as cyanide, pyoverdine, and elastase, but increased pyocyanin production (Linares et al. 2010; Yeung et al. 2011). We hypothesized that $\mathrm{Crc}$ may be involved in the regulation of virulence and other cellular processes in $P$. syringae pv. tomato DC3000 (hereafter referred to as DC3000). In this study, we constructed a $\operatorname{crc}$ deletion mutant of DC3000 and investigated the role of this protein in multiple virulence-related phenotypes.

\section{RESULTS}

\section{Disruption of DC3000 $\mathrm{crc}$ alters motility.}

To investigate the role of $\mathrm{Crc}$ in DC3000, we constructed a deletion mutant in DC3000 and investigated whether disruption of Crc affected virulence-related phenotypes. The first phenotypes we investigated were swimming and swarming motilities. The DC3000 $\Delta c r c$ strain showed increased swarming compared with the wild-type (WT) strain when tested on nutrient broth (NB) medium with glucose (NBG) and minimal media plates containing either fructose, succinate, or mannitol as the sole carbon source (Fig. 1). In minimal media with glucose as the sole carbon source, swarming of $\Delta c r c$ was reduced compared with that in WT. We also observed that $\Delta c r c$ displayed very little to no growth in liquid minimal medium supplemented with glucose (data not shown). The $\operatorname{crc}$ gene was cloned and was used to complement in trans the $\Delta c r c$ strain. Swarming was lower than WT levels when $\Delta c r c$ is complemented (Fig. 1), presumably because overexpression of $\mathrm{Crc}$ leads to a tighter control of target genes than in WT. No difference in swimming was observed between the WT, $\Delta c r c$, and complemented strain (data not shown).

\section{Deletion of $\operatorname{crc}$ results in increased biofilm formation.}

Since $P$. aeruginosa mutants that display altered swarming also are influenced in their ability to form biofilms (Wang et al. 2014), we tested the ability of the DC3000 $\Delta c r c$ mutant to form a biofilm, using the microtiter biofilm cell attachment assay (O'Toole 2011). The $\Delta c r c$ strain showed an enhancement in biofilm formation in comparison with the WT strain when performed under static conditions, using mannitol as the carbon source (Fig. 2A). However, under shaking conditions, we did not observe a difference in biofilm formation (Fig. 2A). In addition, we performed the biofilm experiments using various carbon sources (Supplementary Fig. S1). Biofilm formation was similar between the WT and $c r c$ mutant except when glucose was present and cultures were shaken, when we observed an increase in biofilm formation for the crc mutant compared with the WT. Contrary to the literature, we did not observe an inverse correlation between swarming and biofilm formation in the different media, with the exception of glucose. Biofilm formation was not restored to WT levels in the complemented strain in all cases (Fig. 2A). We hypothesize that, because a multicopy plasmid was used for the complementation, overexpression of $\mathrm{Crc}$ is occurring and this results in a different phenotype, depending on the media. No growth differences were observed when the optical density at $600 \mathrm{~nm}$ $\left(\mathrm{OD}_{600}\right)$ of planktonic cells was measured as a function of time during the period of growth in the microtiter wells (data not shown).

\section{The crc mutant is not altered in EPS production.}

The enhanced biofilm formation of the $\Delta c r c$ mutant led us to investigate whether this mutant was altered in EPS production. Cellulose, Psl, and Pel have been shown to play a role in biofilm formation and swarming (Schurr 2013; Ude et al. 2006). While other strains of Pseudomonas contain the locus for Pel, $P$. syringae DC3000 does not contain this locus (Buell et al. 2003). Psl and cellulose polysaccharides can be observed by the addition of the dye Congo red to media. The strains were grown on Luria medium (LM) or NB agar containing $40 \mu \mathrm{g}$ of Congo red per milliliter. After three days of growth, there was no difference in Congo red-binding between the WT, $\Delta c r c$, or crccomplemented strain $(\Delta c r c[\mathrm{pCrc}])$ when grown on LM or NB agar plates (Fig. 2B), suggesting that the EPS composition of the $\Delta c r c$ strain was not altered. The $\Delta c b r A$ strain (Filiatrault et al. 2013) was used as a positive control, since this mutant has been shown to display enhanced binding of Congo red (Yeung et al. 2011).

\section{Crc plays a role in virulence of $P$. syringae $\mathrm{DC} 3000$.}

In order to test the involvement of Crc in virulence, both Arabidopsis and tomato plants were dip-inoculated in suspensions of WT and the $\Delta c r c$ mutant. The $\Delta c r c$ mutant caused fewer disease symptoms as compared with WT on both species (Fig. 3A and B). We also evaluated symptom formation in syringe-inoculated tomato leaves and observed that $\Delta c r c$ 
caused reduced symptoms, as seen by reduced chlorosis, compared with the WT strain (Fig. 3C). We performed growth assays in dip-inoculated Arabidopsis plants and observed that the $\Delta$ crc mutant grew less than WT (Supplementary Fig. S2).

We then performed bacterial growth assays in dip- or syringe-inoculated tomato and found that the $\Delta c r c$ mutant displayed reduced growth compared with the WT strain at earlier time points (Fig. 4). Lower growth was significantly different 4 or 2 days postinoculation in dipped or syringeinoculated plants, respectively. The growth of $\Delta c r c$ was still lower than WT at later time points, but the difference in growth between the strains was not statistically significant (Fig. 4). Therefore, disease symptoms or growth of $\Delta c r c$, or both, were reduced, irrespective of the mode of bacterial entry into plant tissues in both tomato and Arabidopsis (dipping versus syringe infiltration). Based on these results, we conclude that $\mathrm{crc}$ is necessary for initial growth and fitness in planta.

\section{Deletion of Crc reduces the ability to elicit HR.}

DC3000 elicits a HR in tobacco and $N$. benthamiana (Alfano et al. 1997; Wei et al. 2007). The HR is a localized defense response associated with immunity and involves rapid, programmed plant cell death (Coll et al. 2011; Greenberg and Yao 2004). We found that the $\Delta c r c$ strain showed reduced or delayed HR in $N$. benthamiana and tobacco compared with the WT strain (Fig. 5A). Delayed HR was also observed in tobacco, but the number of times the $\operatorname{crc}$ mutant caused delayed HR was not found to be significant. This phenotype was restored when the crc mutant was complemented (Fig. 5A). Since the HR response due to $\Delta c r c$ was reduced but not abolished, we used a cell-death scoring system in order to obtain a better comparison between $\Delta c r c$ and WT in $N$. benthamiana (Fig. 5B). This scoring system has been used previously to compare samples undergoing cell death (Oh et al. 2010; Rosli et al. 2013) and categorizes the degree of cell death observed into different classes, allowing for better visualization of the data. This analysis clearly shows that overall $\Delta c r c$ is reduced in the ability to elicit HR. A comparison was made between the total number of times full HR was observed in inoculated leaf areas of WT (28 of 33 times) versus $\Delta c r c$-inoculated leaf areas (eight of 33 times), in six independent experiments. Fisher's exact test showed that $\Delta c r c$ was significantly different from WT $(P<0.05)$.

We compared growth of WT versus $\Delta c r c$ in $N$. benthamiana leaves undergoing HR and found that they grew to similar levels $18 \mathrm{~h}$ after inoculation (Supplementary Fig. S3).

\section{The Crc mutant is not affected in its ability to translocate effectors.}

Since $\Delta c r c$ displayed a delayed or reduced HR phenotype and decreased virulence, we speculated about the ability if the crc mutant to translocate effectors efficiently into plant cells. $\mathrm{Crc}$ has been shown to play a role in the regulation of T3SS genes in $P$. aeruginosa (Dong et al. 2013). In order to test
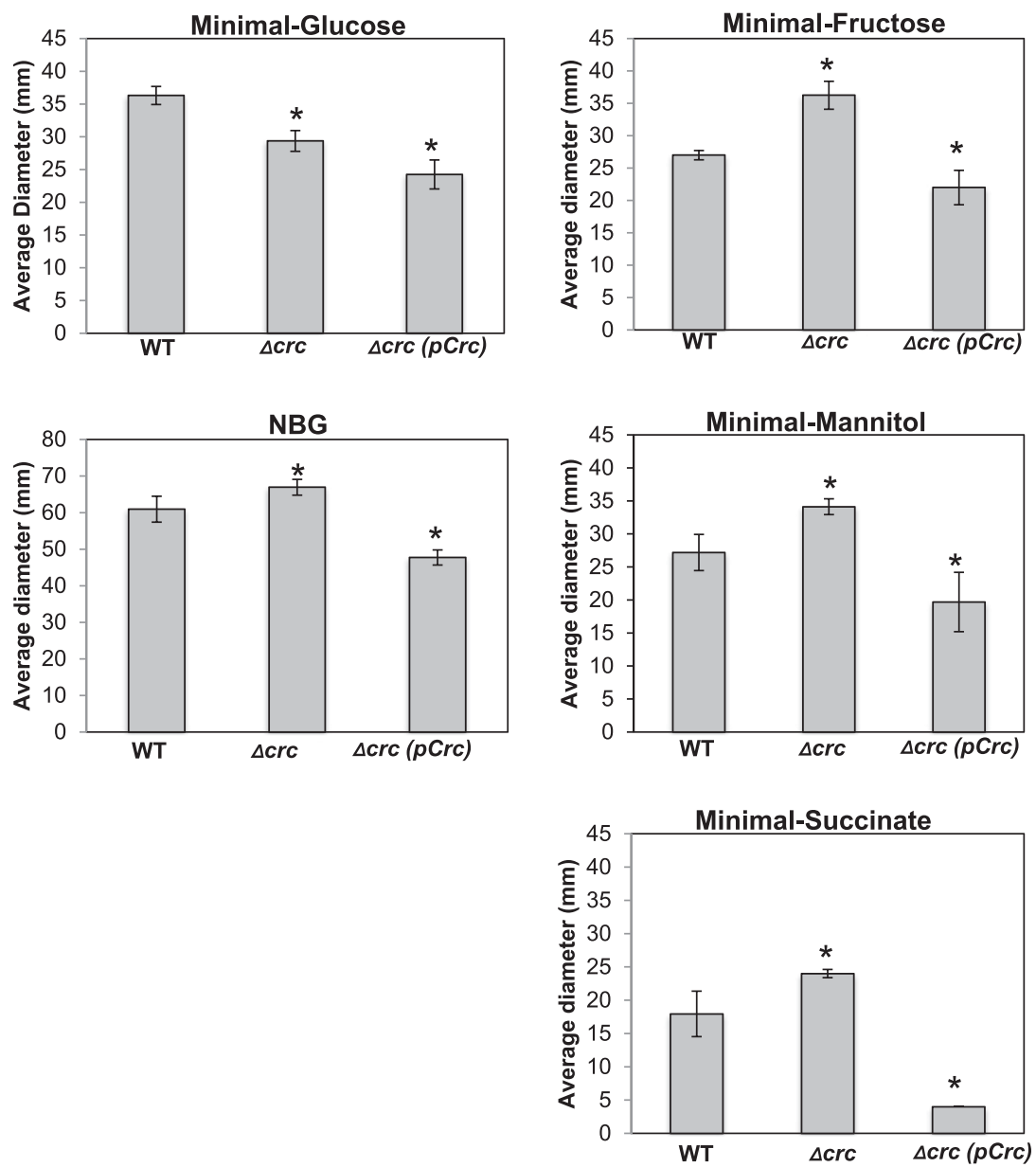

Fig. 1. Inactivation of $c r c$ increases swarming motility of Pseudomonas syringae. Average diameter of swarming colonies with standard deviations of $P$. syringae strains measured after $24 \mathrm{~h}$ growth at $28^{\circ} \mathrm{C}$. Swarming was evaluated in minimal media with glucose, fructose, mannitol, or succinate as the sole carbon source, and nutrient broth medium with glucose (NBG). The samples significantly different from wild type (WT), as measured using student's $t$ test $(P<0.05)$, are shown with an asterisk. The experiment was repeated three times with similar results. The vertical bars represent the standard deviation of the mean. 
T3SS-mediated effector delivery in $\Delta c r c$, we performed an effector translocation assay using the adenylate cyclase (Cya) reporter protein fused to the AvrPto effector (Schechter et al. 2004).

Accumulation of cAMP, a product of Cya activity, was measured in $N$. benthamiana leaves inoculated with WT DC3000 and $\Delta c r c$ expressing AvrPto-Cya (Fig. 5C). Both strains were found to translocate at similar levels, while little cAMP accumulation occurred when leaves were inoculated with the DC3000 T3SS-deficient mutant expressing AvrPtoCya. Therefore, since $\Delta c r c$ translocates AvrPto-Cya as well as WT DC3000, this suggests that the $\Delta c r c$ mutant strain has a functional T3SS and the reduced HR and virulence phenotypes observed are due to other factors.

\section{Crc influences susceptibility}

\section{to reactive oxygen species ( $\mathrm{ROS})$ in $P$. syringae.}

$\mathrm{HR}$ is characterized by the induction of defense responses, including production of active oxygen species and synthesis of antimicrobial compounds like phytoalexins (Coll et al. 2011; Greenberg and Yao 2004). Therefore, we investigated whether the presence of hydrogen peroxide altered the growth of the $\Delta c r c$ strain. Disruption of $c r c$ rendered the bacteria more sensitive to $\mathrm{H}_{2} \mathrm{O}_{2}$ at a concentration of $0.0225 \%$ in liquid King's $\mathrm{B}$ (KB) medium after $8 \mathrm{~h}$ of growth (Fig. 6A). Growth was restored in the complemented strain. This suggests that $\mathrm{Crc}$ may play a role in the response to $\mathrm{H}_{2} \mathrm{O}_{2}$ stress.
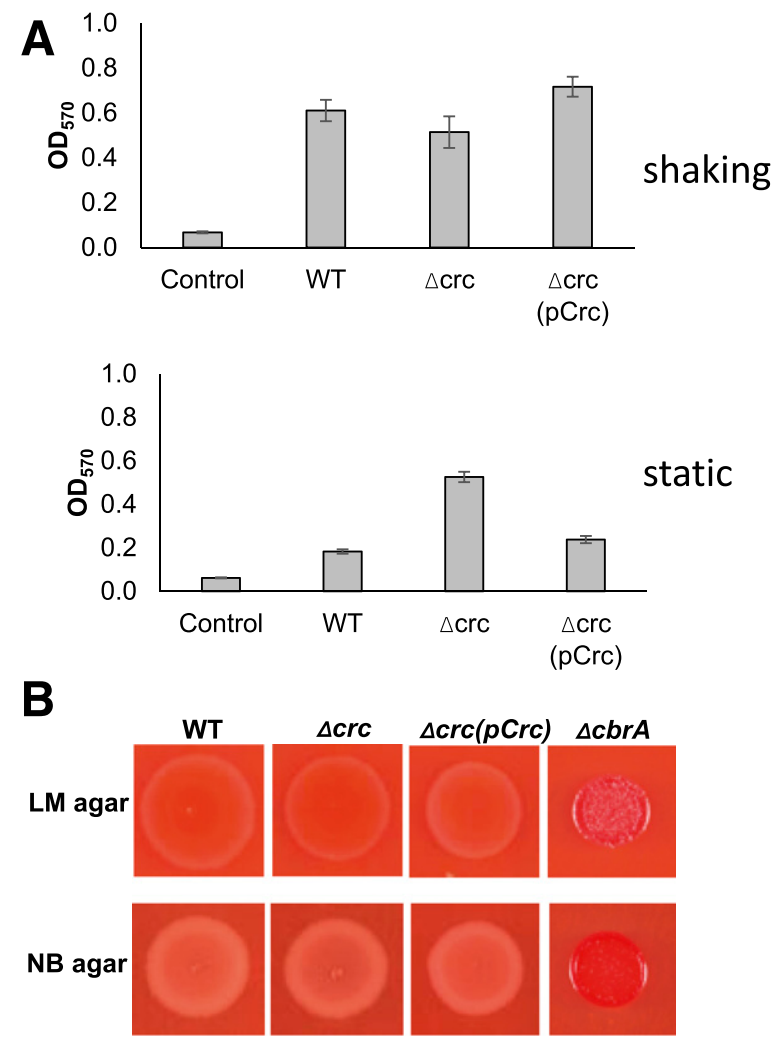

Fig. 2. Inactivation of $c r c$ causes an increase in biofilm formation under static conditions but does not affect exopolysaccharide (EPS) production. A, Biofilm formation in mannitol-glutamate medium was measured by the crystal violet-staining method and was expressed as optical density at 570 $\mathrm{nm}\left(\mathrm{OD}_{570}\right)$. B, The indicated strains were spotted onto Luria medium (LM) or nutrient broth (NB) agar media containing $40 \mu \mathrm{g}$ of Congo red per milliliter. The addition of Congo red to the media is to visualize EPS production. The $\Delta c b r A$ strain was used as a positive control. Plates were photographed 2 days after spotting and the experiment was repeated two times with similar results.
The $\Delta c r c$ strain is more sensitive to PTI.

Preinoculation of $N$. benthamiana leaves with a nonpathogen such as $P$. fluorescens to induce PTI followed by challengeinoculation of an avirulent bacterium abolishes or delays HR because of the induction of PTI (Oh et al. 2010). We hypothesized that if the $\Delta c r c$ mutant was more sensitive to PTI, we would observe total abolishment or even a more significant delay in HR when PTI is induced. To test this hypothesis, we used the overlapping challenge assay in $N$. benthamiana (Chakravarthy et al. 2009) to compare the ability to elicit HR in PTI-induced versus noninduced tissues. $N$. benthamiana leaves were inoculated with WT $P$. fluorescens, which induces PTI and a ROS response or with $P$. fluorescens $\Delta f l i C$, which is unable to elicit PTI and ROS (Oh et al. 2010; Wei et al. 2013), and, $7 \mathrm{~h}$ later, overlapping challenge inoculations were performed with $\Delta c r c$ or WT bacteria.

Cell death due to WT was seen by $24 \mathrm{~h}$ in the nonoverlapping area (Fig. 6B), but $\Delta c r c$, as expected, did not cause cell death in overlapping or non-overlapping areas at this same time point. After $48 \mathrm{~h}$, the WT began to show partial HR in the overlapping areas, in contrast to $\Delta c r c$ where little to no HR was observed in the overlapping areas in which PTI was induced (Fig. 6B and C). $\Delta c r c$ caused HR in overlapping areas in control samples in which PTI was not induced ( $P$. fluorescens $\Delta$ fliC or buffer). We quantitated the HR in overlapping areas of infiltration at $48 \mathrm{~h}$, using a cell-death scoring system (Fig. 6C) (Oh et al. 2010; Rosli et al. 2013). We compared the number of times partial to full cell death was observed in overlapping areas challenged with WT (10 of 19) versus $\Delta c r c$ (three of 19) in three independent experiments. Fisher's exact test showed that $\Delta \mathrm{crc}$

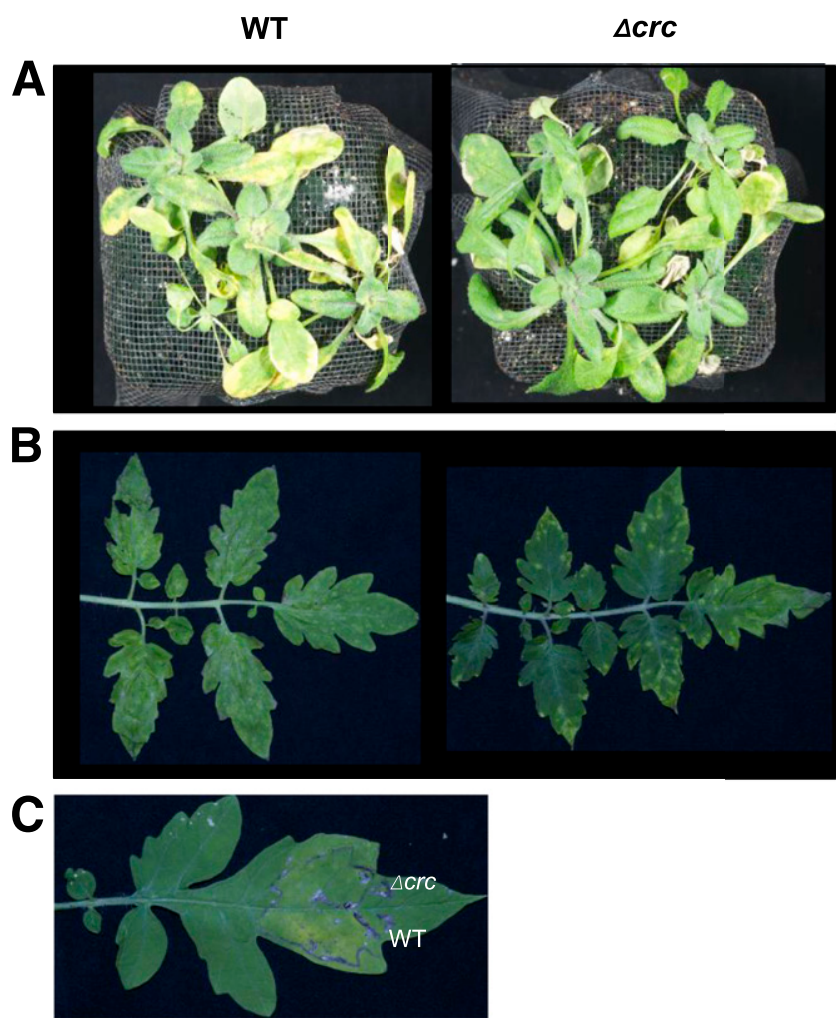

Fig. 3. Pseudomonas syringae pv. tomato DC3000 $\Delta c r c$ causes reduced disease symptoms. A, Arabidopsis plants were dip-inoculated with wild type (WT) or $\Delta c r c$ at $1 \times 10^{7} \mathrm{CFU} / \mathrm{ml}$. B, Tomato plants were dip-inoculated with WT or $\Delta c r c$ at $3 \times 10^{7} \mathrm{CFU} / \mathrm{ml}$. C, Tomato leaves were syringeinoculated with WT or $\Delta c r c$ at $1 \times 10^{4} \mathrm{CFU} / \mathrm{ml}$. Representative photographs were taken 4 days after Arabidopsis dip-inoculation and tomato syringeinfiltration and 6 days after tomato dip-inoculation in all treatments. The experiments were repeated at least five times with similar results. 
was significantly different from WT $(P<0.05)$. Our results, therefore, show that the ability of $\Delta c r c$ to elicit HR is further reduced in PTI- induced tissues. Taking into account our observation that $\Delta c r c$ is sensitive to $\mathrm{H}_{2} \mathrm{O}_{2}$ stress in cultures (Fig. 6A), we hypothesize that $\Delta c r c$ may be affected by ROS during the PTI response.

\section{The $\Delta c r c$ mutant elicits similar levels of PTI marker gene expression and ROS production compared with WT in $N$. benthamiana leaves.}

We speculated that if the $\Delta c r c$ mutant elicited a different PTI response in plants compared with WT, this may render the mutant more sensitive to ROS produced during PTI. We measured the expression of known PTI marker genes, described previously (Nguyen et al. 2010), in N. benthamiana leaves inoculated with WT or $\Delta c r c$. Since WT would elicit HR, we chose to examine gene expression $3 \mathrm{~h}$ postinoculation, prior to the translocation of type III effectors (Anderson et al. 2014; Pombo et al. 2014). This earlier time point should measure the gene expression in response to microbe-associated molecular patterns (MAMPs) (or PAMPs). Buffer-inoculated tissue was used as a control. The expression of GRAS2, ACRE31, and Pti5 was induced in tissues inoculated with WT DC3000 as compared with buffer-inoculated control (Fig. 7A). In tissues inoculated with $\Delta c r c$, we found similar levels of induction of all three genes, compared with the buffer control, as seen with WT. Therefore, $\Delta c r c$ and WT induced similar levels of PTI marker gene expression (Fig. 7A).

We also measured the production of ROS in N. benthamiana leaf discs incubated with WT, $\Delta c r c$, or the complemented mutant (Fig. 7B). ROS are produced as an early response to MAMPs

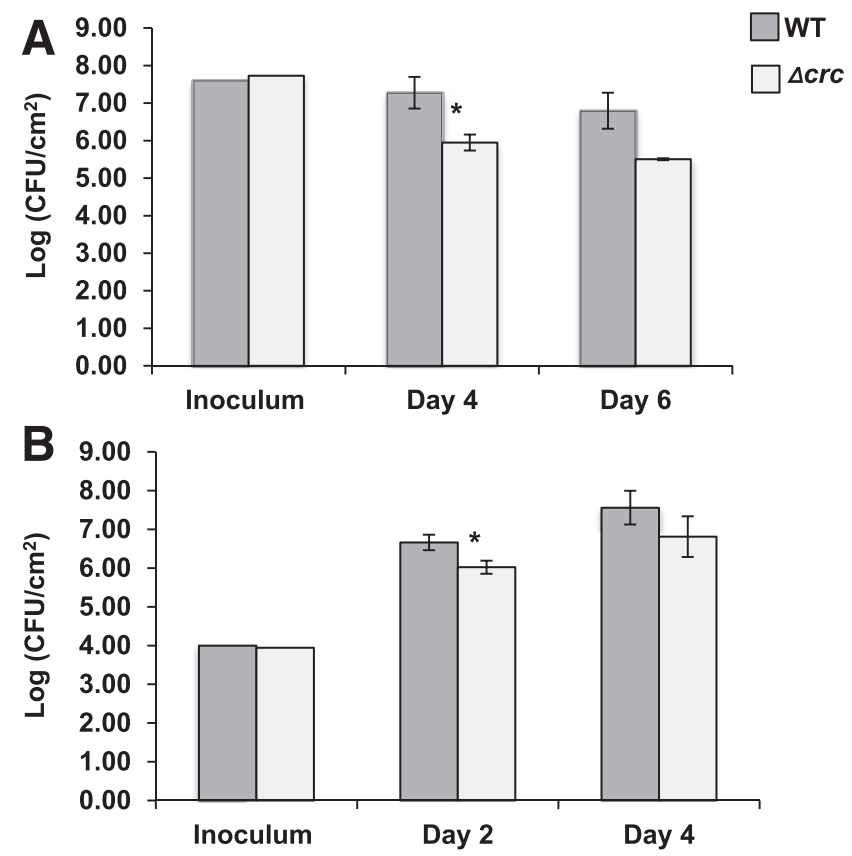

Fig. 4. Pseudomonas syringae pv. tomato DC3000 Acrc shows reduced growth in plants. A, Tomato plants were dip-inoculated with wild type (WT) or $\Delta c r c$ at $3 \times 10^{7} \mathrm{CFU} / \mathrm{ml}$, and bacterial growth was measured 4 and 6 days postinoculation $\mathbf{B}$, Tomato leaves were syringe-infiltrated with WT or $\Delta c r c$ at $1 \times 10^{4} \mathrm{CFU} / \mathrm{ml}$ and bacterial growth was measured 2 and 4 days postinoculation. Growth is depicted as means with standard deviation of average $\log \left(\mathrm{CFU} / \mathrm{cm}^{2}\right)$ from three plants per sample. Inoculum $(\mathrm{Log}[\mathrm{CFU} / \mathrm{ml}])$ is shown. Students $t$ test was performed to analyze statistical significance of growth difference at $P<0.05$, and populations significantly different from WT are indicated with an asterisk. The experiment was repeated five times with similar results. during PTI (Nicaise et al. 2009; Wu et al. 2014). The levels of ROS produced during coincubation of leaf discs and the bacterial strains was similar.

Since no difference was detected in the ability of the $\Delta c r c$ mutant to produce ROS compared with WT or induced gene expression of known PTI marker genes, we investigated whether Crc influences expression of known genes involved in virulence in DC3000. It was also possible that, although the $\Delta c r c$ mutant was able to translocate the effector AvrPto (Fig. 5C), Crc may display altered expression of other components of the type III system or other genes reported to be involved in virulence. Therefore, we isolated RNA from WT and $\Delta c r c$ strains grown in various media and performed quantitative reverse transcription-polymerase chain reaction (qRT-PCR). All the genes we tested showed no significant difference in expression between the WT and the $\Delta c r c$ mutant (Supplementary Fig. S4).

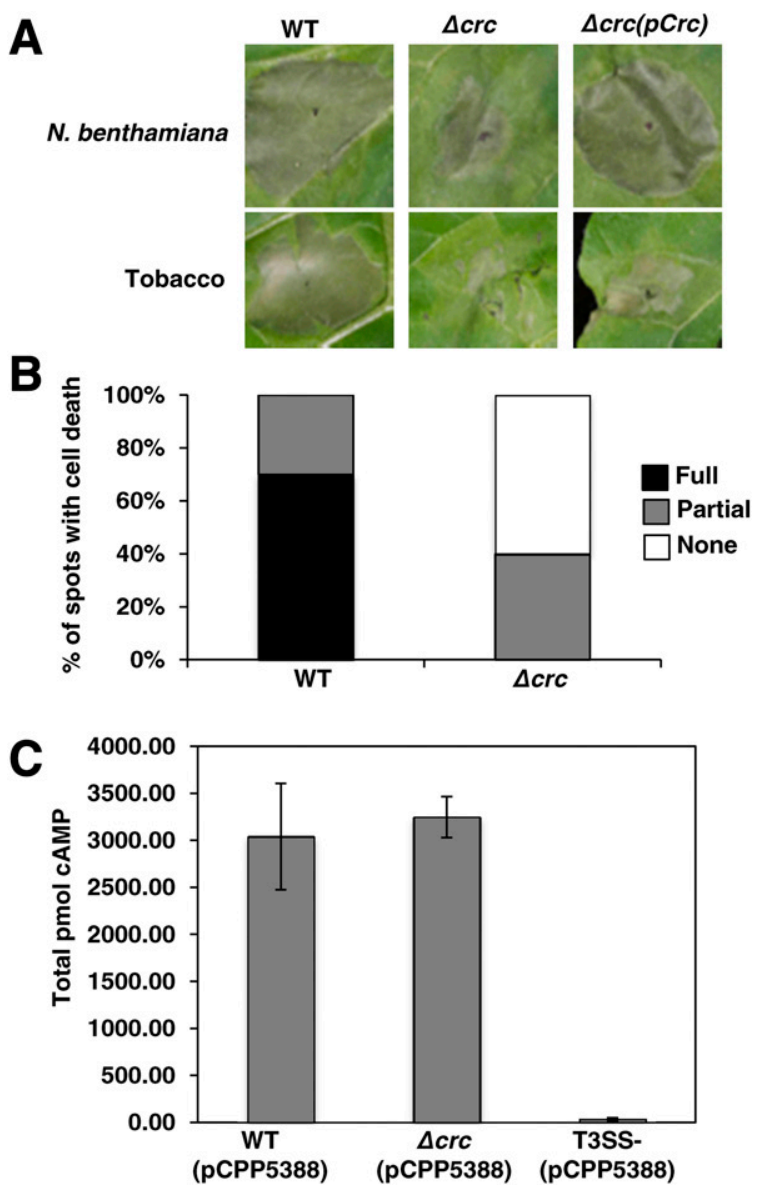

Fig. 5. The $\operatorname{crc}$ mutant causes delayed hypersensitive response (HR) in Nicotiana benthamiana and tobacco and translocates AvrPto-Cya to similar levels as wild-type (WT) DC3000. A, N. benthamiana and tobacco leaves were infiltrated with the indicated strains at $2 \times 10^{7} \mathrm{CFU} / \mathrm{ml}$ (optical density at $600 \mathrm{~nm}=0.02$ ) and were photographed 1 day after inoculation. B, HR cell death in $N$. benthamiana caused by WT and $\Delta c r c$ was scored as full, partial, or none. The number of spots showing cell death in each category was scored, and a $100 \%$ stacked column representing the scoring results is shown. The HR inoculation and scoring experiments were repeated at least three times with similar results. C, DC3000 and $\Delta c r c$ mutant were compared for their ability to translocate the AvrPto-Cya translocation reporter expressed from plasmid pCPP5388 (Lam et al. 2014). The type three secretion system-deficient strain containing pCPP5388 was used as a control. Bacteria were infiltrated into $N$. benthamiana leaves at $5 \times 10^{7} \mathrm{CFU} / \mathrm{ml}$ and, $6 \mathrm{~h}$ later, leaf discs were harvested and the amount of cAMP measured. The average cAMP ( in picomoles) with standard deviation from three plants is shown. The experiment was repeated three times with similar results. 


\section{DISCUSSION}

The posttranscriptional regulator $\mathrm{Crc}$ has been reported to modulate motility, antibiotic susceptibility, and virulence of $P$. aeruginosa (Linares et al. 2010; O'Toole et al. 2000). Interestingly, strain-specific phenotypes for the role of $\mathrm{Crc}$ in bacteria have been observed. For example, a $\mathrm{crc}$ mutant of $P$. aeruginosa PA14 is defective in twitching motility and formation of biofilms (O'Toole et al. 2000), whereas in $P$. aeruginosa $\mathrm{PAO} 1$, lack of Crc leads to reduced swarming and increased cell aggregation (Linares et al. 2010). In the present study, we show that inactivation of Crc leads to altered motility, cell aggregation, and virulence of $P$. syringae pv. tomato DC3000. The reduced virulence appears to be independent of the T3SS, but due, rather, to an increased susceptibility to PTI.

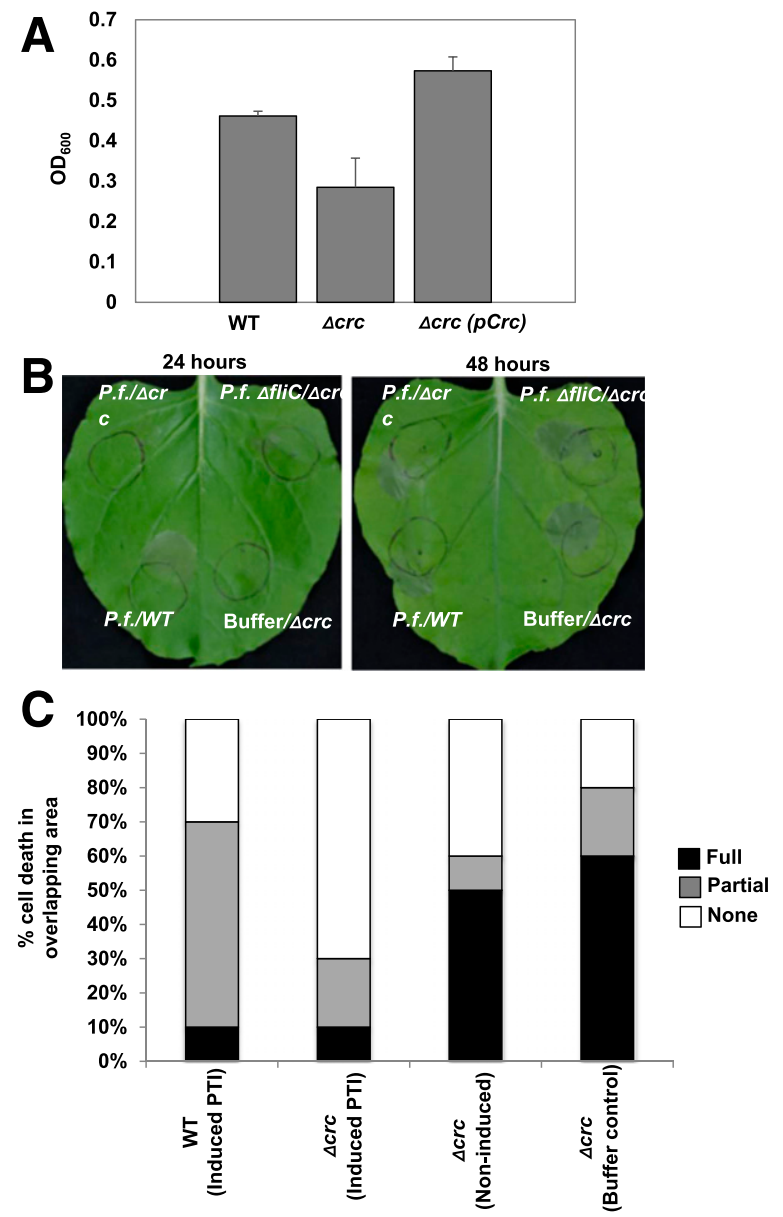

Fig. 6. Susceptibility to hydrogen peroxide and pathogen-associated molecular pattern-triggered immunity (PTI) for the wild type (WT) and $\Delta c r c$ mutant. A, The optical density of the indicated strains was compared by the addition of hydrogen peroxide at $0.0225 \%$ for the WT, $\Delta c r c$ mutant, and complemented strains. The experiment was repeated three times and the values were averaged. Vertical bars represent standard deviation of the mean. B, Susceptibility to PTI using the overlapping challenge assay. Nicotiana benthamiana leaves were syringe-infiltrated with Pseudomoonas fluorescens or P. fluorescens lacking fliC. $($ P.f. $\Delta f l i C)$ at $5 \times 10^{8} \mathrm{CFU} / \mathrm{ml}$. Buffer was used as a control. The spots were challenged, $7 \mathrm{~h}$ later, with WT DC3000 or $\Delta c r c$ at $2 \times 10^{7} \mathrm{CFU} / \mathrm{ml}$. The areas inoculated with $P$. fluorescens or $P$. fluorescens $\Delta$ fliC are circled with a black marker. Photographs were taken 24 or $48 \mathrm{~h}$ post-challenge inoculation to observe cell death outside or inside the area of overlapping infiltration. C, Hypersensitive response (HR) cell death in the overlapping area of infiltration was scored as full, partial, or none. HR due to WT or $\Delta c r c$ in PTI-induced or noninduced tissues is shown as a $100 \%$ stacked column. Five to ten plants were inoculated in each experiment and the experiment was repeated three times with similar results.
The pseudomonads can perform various forms of motility. Swimming motility is defined as movement of a single bacterium in a liquid or low-viscous medium and requires functional flagella. Swarming motility, which is coordinated multicellular movement (or group behavior) across a semisolid surface, also involves flagellum but, in addition, requires the presence of other factors, such as biosurfactants. It was also recently demonstrated that DC3000 performs a type of motility, a sliding movement, that is flagella-independent but syringofactindependent (Nogales et al. 2015). Motility plays an important role in the ability of bacteria to colonize different environments and attach to surfaces and in the subsequent formation of cell aggregates or cell-associated communities called biofilms. Reports indicate that there is an inverse relationship between swarming ability and cell aggregation, or biofilm formation (Caiazza et al. 2007), in $P$. aeruginosa. In most cases, impaired motility results in enhanced biofilm formation and vice versa. Therefore, it was surprising to see that the $\operatorname{crc}$ mutant in DC3000 demonstrated both an increase in swarming and biofilm formation. However, differences in biofilm formation were dependent upon media and whether or not cultures were static or shaking. Since swimming motility was not affected, this

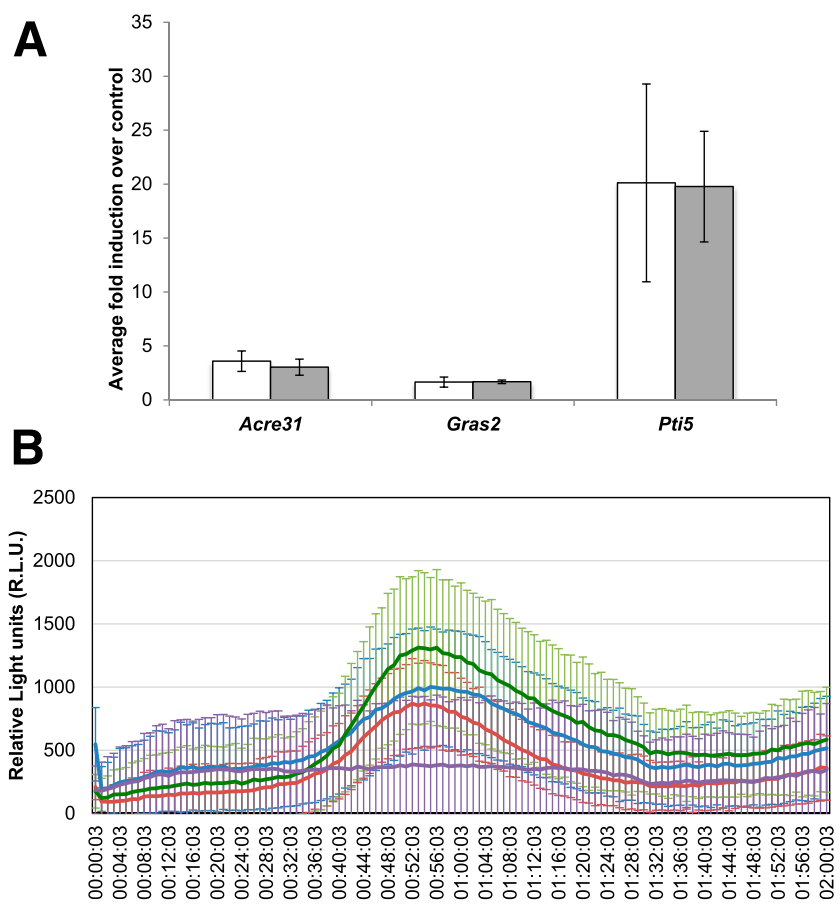

Fig. 7. Induction of pathogen-associated molecular pattern-triggered immunity (PTI) reporter genes Acre31, Gras2, and Pti5 and reactive oxygen species (ROS) elicitation by wild type (WT) and $\Delta c r c$ in Nicotiana benthamiana. A, $N$. benthamiana leaves were syringe-infiltrated with $2 \times 10^{8}$ $\mathrm{CFU} / \mathrm{ml}$ of WT or $\Delta c r c$ and $10 \mathrm{mM} \mathrm{MgCl}_{2}$ was infiltrated as a control. Leaf samples were harvested after $3 \mathrm{~h}$ and RNA was isolated. Quantitative reverse transcription-polymerase chain reaction was performed using cDNA prepared from the different samples. The fold induction of reporter genes in WT- or $\Delta c r c$-inoculated samples over that in control samples was calculated using the cycle threshold $\left(2^{-\Delta \Delta C t}\right)$ method. The average fold induction over control of three plants per strain with standard deviation is shown. The experiment was repeated three times with similar results. Students $t$ test revealed no significant differences in the level of induction of genes between WT and $\Delta c r c(P<0.05)$. B, Leaf discs were excised and incubated with $12 \times 10^{7} \mathrm{CFU} / \mathrm{ml}$ of DC3000 WT (blue line), $\Delta c r c$ (red line), $\Delta c r c$ ( $p C r c$ ) (green line), or $10 \mathrm{mM} \mathrm{MgCl}_{2}$ (purple line) as control. Production of ROS over time was measured using a L-012-based chemiluminescence assay. The average relative light units (R.L.U.) for at least 40 leaf discs per strain with standard deviation is shown. Measurements were taken every 4 min over $2 \mathrm{~h}$. Students $t$ test revealed no significant differences in ROS production between WT and $\Delta c r c$ or $\Delta c r c(p C r c)(P<0.05)$. 
suggests that the $\operatorname{crc}$ mutant is not attenuated in the functionality of flagella. We also found that expression of $\mathrm{fliC}$ was similar between the strains in the different media. However, our observations that disease symptoms were reduced during dipinoculation and syringe-infiltration (Fig. 3) may imply that flagellar function is somehow affected in the $\operatorname{crc}$ mutant, since dip-inoculation would require flagella for entry into plant tissue.

We chose to investigate the production of the EPSs, Psl, and cellulose, using a Congo red binding assay, since cellulose has also been identified as a matrix component in other Pseudomonas spp. biofilms, including P. syringae (Ude et al. 2006). There were no noticeable differences in production of these molecules by the DC3000 crc mutant. This is in contrast to $P$. aeruginosa, in which the $\operatorname{crc}$ mutant displays Congo red binding. The observation that the $\operatorname{crc}$ mutant in DC3000 does not demonstrate differences in Congo red binding like that in $P$. aeruginosa suggests different pathways of regulation in the plant pathogen $P$. syringae.

Swarming motility, a coordinated movement of bacterial cells across a semisolid surface (Déziel et al. 2003), generally requires production of a surface wetting material or surfactant, like rhamnolipids or rhamnolipid precursors 3-(3-hydroxyalkanoyloxy) alkanoic acid (HAA). In P. aeruginosa, mono- and di-rhamnolipids as well as HAAs are secreted during swarming. The production of HAA has been shown by $P$. syringae pv. syringae $\mathrm{B} 728$ a (Burch et al. 2012). $P$. syringae pv. syringae $\mathrm{B} 728 \mathrm{a}$ also produces lipopeptides called syringofactins, shown to be involved in swarming motility (Berti et al. 2007; Burch et al. 2010). It should be noted that $P$. syringae pv. syringae B728a and DC3000 differ in their lifestyles, with B728a displaying a more pronounced epiphytic growth stage in contrast to DC3000, which is considered a weak epiphyte (Boureau et al. 2002; Xin and He 2013). Although we did not investigate the ability of the $\operatorname{crc}$ mutant to produce surfactants, it is possible that the $c r c$ mutant has enhanced production of these molecules. Since motility, in particular HAA-mediated swarming, is favored in an epiphytic environment rather than in planta (Yu et al. 2013), one might speculate that enhanced swarming or biofilm formation may be detrimental to DC3000 once inside the plant cell. Recently, it was shown that Pseudomonas cichorii mutants unable to produce a lipopeptide called cicofactins displayed enhanced biofilm formation and were less pathogenic than the WT strains, due to the inability to spread within the plant (Pauwelyn et al. 2013).

Inactivation of the $\operatorname{crc}$ gene leads to reduced virulence. One explanation may be the effect $\mathrm{Crc}$ has on metabolism of the bacterium in the apoplast. In planta, the sugars fructose, sucrose, and citrate are highly abundant. To allow expression of these metabolic pathways that are involved in utilization of these sugars, Crc would be need to be sequestered. Sequestration would likely involve the small RNA $\operatorname{crc} Z$ and $\operatorname{crc} X$. Indeed, we have shown in vitro that deletion of the small RNA $\operatorname{crc} Z X$ results in reduced ability to grow in media in which fructose and other sugars are provided as the main carbon source (Filiatrault et al. 2013). Therefore, the deletion of both $c r c Z$ and $c r c X$ might result in reduced growth and symptoms in planta. However, a $\operatorname{crcZX}$ deletion strain is still able to cause disease and HR (data not shown). Alternatively, $P$. syringae could preferentially use the most abundant amino acids present in apoplastic fluid (GABA, aspartic acid, glutaric acid, alanine, serine, and glutamine) (Park et al. 2010; Rico and Preston 2008) and alleviate the need to relieve Crc-mediated repression of the pathways involved in, e.g., fructose and citric acid. However, studies evaluating the transcriptional response of $P$. syringae B728a have shown that genes involved in the metabolism of sucrose and inositol as well as genes for GABA metabolism were up-regulated in bacteria growing in the apoplast compared with bacteria on the leaf surface (Yu et al. 2013). Unfortunately, this study could not determine the regulation of genes involved in fructose, mannitol, and succinate in planta, because these components were present in the basal medium. The fact that the crc mutant displays reduced virulence and reduced growth in planta suggests that, in addition to regulating expression of nutritional factors, $\mathrm{Crc}$ regulates other factors important for virulence. Interestingly, the intracellular signaling molecule cyclic di-GMP (c-di-GMP) is a secondary messenger that controls the switch between single-celled motile and sessile lifestyles in Pseudomonas spp. (Valentini and Filloux 2016). Cdi-GMP is responsible for the regulation of biofilm formation, dispersion, motility, EPS production, the cell cycle, and virulence (Römling et al. 2013). For P. syringae DC3000, increasing c-di-GMP concentrations reduced motility and increased biofilm formation (Pérez-Mendoza et al. 2014). In addition, elevated c-di-GMP levels in DC3000 inhibit flagellin synthesis, allowing bacteria to evade PTI (Engl et al. 2014; Pfeilmeier et al. 2016). However, virulence is reduced when cdi-GMP levels are increased (Engl et al. 2014; Pfeilmeier et al. 2016). Since disruption of Crc also influences motility, biofilm formation, and virulence in DC3000, one might speculate crosstalk between pathways regulated by $\mathrm{Crc}$, such as catabolite repression and c-di-GMP. Although catabolite repression occurs via another mechanism in Xanthomonas spp., it has been shown that expression of the GGDEF domain protein XCC2731 is regulated by carbon source (Hsiao et al. 2011). Therefore, it may be worth investigating whether Crc impacts expression of c-di-GMP proteins in $P$. syringae DC3000.

The virulence of $P$. syringae DC3000 relies on the activity of effectors delivered by the T3SS and on the phytotoxin coronatine, which plays an important role in symptom development (Xin and He 2013). The crc mutant caused reduction of either virulence symptoms, growth, or both in tomato and Arabidopsis. The infected plants still showed some symptoms of bacterial speck disease in tomato and chlorosis in Arabidopsis, suggesting that coronatine function was not affected. The $\operatorname{crc}$ mutant also did not display growth defects in vitro (data not shown). Therefore, we ruled out the possibility that reduced virulence resulted from the lack or inability to metabolize carbohydrates in plant tissues.

The first line of active plant defense is PTI, which involves detection of conserved microbial factors, such as bacterial flagella, peptidoglycan, and lipopolysaccharides, via hostpattern recognition receptors (Monaghan and Zipfel 2012). Successful pathogens are able to overcome PTI, due to the virulence activity of secreted effectors. The recognition of effectors by plant resistance genes leads to the second line of defense, effector-triggered immunity (ETI), which is stronger and more effective at restricting the spread of pathogens. The HR has been proposed to be a manifestation of ETI. It is a localized defense response and involves rapid, programmed plant cell death (Coll et al. 2011; Greenberg and Yao 2004). The $\operatorname{crc}$ mutant caused delayed or reduced HR in tobacco and $N$. benthamiana, but because effector translocation was not altered, this indicates that the T3SS is functional in the $c r c$ mutant. Furthermore, since the mutant is still able to eventually elicit HR in $N$. benthamiana, this also suggests that HopQ1-1mediated HR has not been disrupted in the $\operatorname{crc}$ mutant, since HopQ1-1has been identified as an avirulence determinant in $N$. benthamiana (Wei et al. 2007). Further, our qRT-PCR data also examined the expression of $\operatorname{hop} Q 1-1$, and we found that it was expressed to similar levels in WT and the $\operatorname{crc}$ mutant.

The production of ROS is a hallmark of HR and PTI. We wondered if the $\operatorname{crc}$ mutant was more sensitive to ROS, and indeed, we found that it was more sensitive to oxidative stress 
compared with the WT strain in vitro. Furthermore, our experiment with the challenge assay also showed that PTI causes a delay in $c r c$-mediated HR, likely due to PTI-mediated ROS production. Although our results suggest that reduced virulence and altered ability to elicit HR is due to an increase in sensitivity to ROS, we cannot rule out that $\Delta c r c$ is affected in the number or presentation of PAMPs.

We chose to study the expression of T3SS-related regulatory or structural genes $h r p L, h r c C$, hrpR, T3E hopQ1-1 (Lam et al. 2014), flagellar component fliC (Haefele and Lindow 1987), harpin hrpZ (Preston et al. 1995), phytotoxin coronatine synthesis regulator corR (Sreedharan et al. 2006), and carbohydrate metabolism genes pgm and mqo (Mellgren et al. 2009; Morris et al. 1995). These genes have prior demonstrated roles in the virulence of $P$. syringae. We examined gene expression in rich medium (NB), in which Crc would be predicted to bind to its targets, and in minimal media supplemented with $\mathrm{Fe}$, which has been shown to turn on the expression of T3SS genes (Bronstein et al. 2008). We observed that there was no significant up- or downregulation of any of the genes in $c r c$ compared with WT under all conditions tested.

Analysis of predicted Crc-binding sites in Pseudomonas genomes (Browne et al. 2010) suggests that some targets are genus-wide and are related to central metabolism, whereas other targets are species-specific. There are 143 genes predicted to be directly regulated by $\mathrm{Crc}$ in $P$. syringae DC3000. Crcbinding sites are mostly for genes predicted to be involved in carbohydrate metabolism. There are predicted binding sites in transcripts for algP (alginate metabolism), PSPTO_3494 (myoinositol 2-dehydrogenase), proteins involved in chemotaxis, and several transcriptional regulators. None of the predicted targets appear to be directly involved in susceptibility to oxidative stress. Future work to investigate the effect $\mathrm{Crc}$ has on one or both the global transcriptome or proteome of $P$. syringae DC3000 would help elucidate more specifically the direct and indirect roles $\mathrm{Crc}$ plays in nutrient acquisition and virulencerelated traits of $P$. syringae DC3000.

The determination of Crc-binding sites in DC3000 would help explain the effects seen on virulence, motility, and sensitivity to ROS. It is clear that Crc plays a broad role in DC3000 virulence, in addition to its role in carbohydrate metabolism. One possibility is that the increased swarming and biofilm formation seen may be detrimental to the $\operatorname{crc}$ mutant for plant cell contact and deployment of the T3SS, thereby causing the observed delay in HR and reduced growth in planta. As such, components of the T3SS seem unaffected in the mutant, as seen by the virulence gene expression and effector translocation studies. The initial entry of the $\operatorname{crc}$ mutant into apoplastic space may be similar to WT, as suggested by normal flagellar function in swimming experiments and WT levels of $f l i C$ gene expression in qPCR. Experiments with PTI marker genes and ROS production indicate that the mutant does not elicit an altered PTI response, which implies that major PAMPS are not different in the $c r c$ mutant. Therefore, we might speculate that the $c r c$ mutant can enter the plant leaf equally as well as WT but is unable to efficiently colonize because it produces more biofilm and is, also, affected by the ROS. It is likely that DC3000 cells need to individually make contact with plant cells, infect and overcome defenses, and then, establish colonies. Another possibility is that, although we did not observe a difference in swimming in the conditions we tested, flagella are somehow affected, and this may delay entry and, subsequently, delay all stages of the life cycle.

\section{MATERIALS AND METHODS}

Bacterial strains and growth conditions.

The strains and plasmids used for this study are available upon request. Pseudomonas syringae pv. tomato DC3000 was routinely cultured on KB agar (King et al. 1954), NB agar, modified LM (10 g of Bacto tryptone, $6 \mathrm{~g}$ of yeast extract, $0.6 \mathrm{~g}$ of $\mathrm{NaCl}, 0.4 \mathrm{~g}$ of $\mathrm{MgSO}_{4} \cdot 7 \mathrm{H}_{2} \mathrm{O}$, and $1.5 \mathrm{~g} \mathrm{~K}_{2} \mathrm{HPO}_{4}$ per liter) (Hanahan 1983) or mannitol-glutamate (MG) medium (per liter, $10 \mathrm{~g}$ of mannitol, $2 \mathrm{~g}$ of $\mathrm{L}$-glutamic acid, $0.5 \mathrm{~g}$ of $\mathrm{KH}_{2} \mathrm{PO}_{4}$, $0.2 \mathrm{~g}$ of $\mathrm{NaCl}, 0.2 \mathrm{~g}$ of $\mathrm{MgSO}_{4} \cdot 7 \mathrm{H}_{2} 0$, final $\mathrm{pH}$ of 7.0) (Keane et al. 1970) at $28^{\circ} \mathrm{C}$ or at room temperature. Escherichia coli DH5 $\alpha$ or TOP10 (Invitrogen) were used as the host for subcloning and other plasmid manipulations. E. coli was grown at $37^{\circ} \mathrm{C}$ in Luria-Bertani (LB) medium or LB medium solidified with $1.5 \%$ (wt/vol) agar.

\section{Construction of a $\operatorname{crc}$ deletion mutant.}

A Crc (PSPTO_ 0079) deletion mutant $(\Delta c r c)$ was created using a pK18mobsacB plasmid (Schäfer et al. 1994). pK18mobsacB/Acrc was created by PCR amplification of DNA fragments of approximately $1.0 \mathrm{~kb}$ that flank $c r c$. Gel-purified PCR fragments were joined by a second PCR amplification with primers containing $X b a \mathrm{I}$ restriction sites. The product was gel-purified, was digested with XbaI, and was cloned into pK18mobsacB digested with the same restriction enzymes. The pK18mobsacB deletion construct was confirmed by sequencing (Cornell University Life Sciences Core Laboratories Center) before introduction into DC3000 via electroporation. Integration events were selected on KB medium containing $50 \mu \mathrm{g}$ of kanamycin per milliliter and were then transferred to $10 \%$ sucrose medium, to select for crossover events that resulted in the loss of the $s a c B$ gene. Sucrose-resistant colonies were screened by PCR and positive clones (those containing the deletion) were confirmed by sequencing.

\section{Complementation of $\Delta c r c$ mutant.}

The genomic region containing the $\operatorname{crc}$ gene was PCR amplified from DC3000 chromosomal DNA using the primers 5'-GCGCTCTAGACAGTGCGGAACCGGTATTG-3' and 5'ATATTCTAGATCAGATAGTCAGGGTCCAG-3', which contained restriction sites for $X b a \mathrm{I}$. The amplified product was gel-purified, was digested with $X b a \mathrm{I}$, and was cloned into pUCP22 (Schweizer 1991) that had been previously digested with $X b a \mathrm{I}$. The ligation was transformed into E. coli $\mathrm{DH} 5 \alpha$. Transformants were selected on gentamycin. Those colonies containing the correct size inserts, confirmed by sequencing to ensure no mutations, were introduced during PCR. pUCP22 containing the $c r c$ gene (pUCP22:crc) was introduced into the $\Delta c r c$ strain by electroporation. This strain was designated $\Delta c r c$ $(\mathrm{pCrc})$. As a control, pUCP22 was introduced into the WT strain.

\section{Evaluating susceptibility to hydrogen peroxide.}

$\mathrm{DC} 3000$ and $\Delta c r c$ were grown overnight at $28^{\circ} \mathrm{C}$ in $\mathrm{KB}$ liquid medium. The overnight cultures were pelleted and resuspended in fresh liquid $\mathrm{KB}$ to an $\mathrm{OD}_{600}$ of 1.0. Cultures were further diluted to an $\mathrm{OD}_{600}=0.1$ in $200 \mu \mathrm{l}$ of $\mathrm{KB}$ only or KB containing hydrogen peroxide $(0.015,0.0225$, or $0.03 \%)$ in a 96 -well plate. The plate was incubated for $24 \mathrm{~h}$, with shaking, in a BioTek plate reader. The $\mathrm{OD}_{600}$ was recorded after $8 \mathrm{~h}$. Each experiment was performed in triplicate for each concentration of hydrogen peroxide, and a total of three biological replicates were performed. The $\mathrm{OD}_{600}$ values for each technical replicate were averaged and standard deviations were calculated.

\section{Motility assays.}

Swimming medium consisted of tryptone ( $10 \mathrm{~g} / \mathrm{liter})$, sodium chloride ( $7 \mathrm{~g} / \mathrm{liter})$, and $0.3 \%$ agar. Swim plates were inoculated, with a toothpick, with bacteria grown overnight on $\mathrm{KB}$ agar plates. Plates were incubated at room temperature for $48 \mathrm{~h}$. The diameter of the swimming zone was measured at both 24 and $48 \mathrm{~h}$ postinoculation. Swimming assays were performed 
in triplicate for each strain tested and three independent biological replicates were completed. The swimming diameter was averaged for each replicate and standard deviation was calculated.

Swarming medium consisted of nutrient broth ( $8 \mathrm{~g} /$ liter $)$, glucose $(0.5 \%$ [wt/vol]), and $0.5 \%$ (wt/vol) agar (NBG). Different carbon sources, including fructose, glucose, and succinate, were substituted for mannitol in the MG medium to a final concentration of $1 \%(\mathrm{wt} / \mathrm{vol})$. Swarm plates were inoculated with bacteria that had been grown overnight in $\mathrm{KB}$ liquid medium at $28^{\circ} \mathrm{C}$ and adjusted to an $\mathrm{OD}_{600}=0.3$ in $\mathrm{KB}$ liquid medium. Bacterial suspension $(5 \mu \mathrm{l})$ was spotted onto the center of the swarming plate and plates were incubated at room temperature. The diameter of the swarming zone was measured $24 \mathrm{~h}$ postinoculation. Swarming assays were performed in triplicate for each strain tested and three independent biological replicates were completed. The swarming diameter was averaged for each replicate and standard deviation was calculated.

\section{Biofilm formation.}

Biofilm formation was assessed using the microtiter dish biofilm method described by (O'Toole 2011), with some modifications. $P$. syringae strains were grown overnight in $\mathrm{KB}$ liquid medium at $28^{\circ} \mathrm{C}$. Overnight cultures were washed three times with desired medium. The tested medium included MG liquid medium and MG liquid medium in which carbon sources were substituted with fructose, glucose, and succinate at final concentrations of $1 \%$ (wt/vol). For measurable biofilm formation, we modified the established biofilm formation method by allowing the presence of $2 \mathrm{mM} \mathrm{CaCl}_{2}$ in addition to the $100-\mu \mathrm{l}$ $\mathrm{OD}_{600}=0.01$ bacterial suspension in 96-well plates. Bacterial suspensions were added to 96 -well plates prefilled with media to final $\mathrm{OD}_{600}=0.01$ and were allowed to incubate at $28^{\circ} \mathrm{C}$ or room temperature for $24 \mathrm{~h}$, with and without shaking. After $24 \mathrm{~h}$, planktonic cells were removed from wells. Wells were washed gently three times with double-distilled $(\mathrm{dd}) \mathrm{H}_{2} \mathrm{O}$. Approximately $150 \mu \mathrm{l}$ of $0.1 \%$ crystal violet stain was added to each well and was allowed to incubate for $10 \mathrm{~min}$. The stain was removed and wells were washed three times with $\mathrm{ddH}_{2} \mathrm{O}$. Stained biofilms were resuspended in $30 \%$ acetic acid and were allowed to incubate for $10 \mathrm{~min}$. The $\mathrm{OD}_{570}$ was recorded for each well and the average and standard deviation for technical replicates were computed.

\section{Congo red assays.}

$P$. syringae strains were grown overnight in $\mathrm{KB}$ liquid medium, were washed twice with NB or LM media, and were then resuspended in $\mathrm{NB}$ or $\mathrm{LM}$ at an $\mathrm{OD}_{600}$ of 0.3 . Culture $(5 \mu \mathrm{l}$ each) was spotted onto NB agar plates containing $40 \mu \mathrm{g}$ of Congo red per milliliter (Sigma Aldrich). The plates were incubated at $28^{\circ} \mathrm{C}$ and were monitored for a total of 3 days.

\section{Tomato and Arabidopsis dip-inoculation.}

Arabidopsis was grown and dip-inoculated as described earlier (Katagiri et al. 2002). Briefly, the plants were grown at $23^{\circ} \mathrm{C}$ with a 12 -h day and $75 \%$ relative humidity. Three- to four-week-old plants were dipped in bacterial suspensions adjusted to $1 \times 10^{7} \mathrm{CFU} \mathrm{ml}^{-1}$ in $10 \mathrm{mM} \mathrm{MgCl}_{2}$ containing $0.04 \%$ Silwet L-77. Tomato inoculations were performed as described by Park et al. (2013), except that Silwet L-77 was used at a concentration of $0.04 \%$ for the dip assay. Solanum lycopersicum (tomato cultivar Moneymaker) was grown at $23^{\circ} \mathrm{C}$ in a greenhouse, with approximately $16 \mathrm{~h}$ of light per day. Four- to five-week-old plants were first acclimatized on a bench top for $24 \mathrm{~h}$ and were then bagged to create a high-humidity environment for $24 \mathrm{~h}$ prior to dipping. Bacterial suspensions were spread onto KB agar plates and were incubated at $28^{\circ} \mathrm{C}$ for $24 \mathrm{~h}$.
The resulting bacterial lawns were harvested and were adjusted to $3 \times 10^{7} \mathrm{CFU} \mathrm{ml}{ }^{-1}$ in $10 \mathrm{mM} \mathrm{MgCl}_{2}$. Tomato plants were dipped in this suspension for $30 \mathrm{~s}$. The inoculum was serially diluted and was plated on $\mathrm{KB}$ containing $50 \mu \mathrm{g}$ of rifampicin per milliliter to verify the bacterial concentration. Following bacterial inoculation, tomato plants were allowed to air dry on the bench for $1 \mathrm{~h}$, then, were incubated in a growth chamber at $25^{\circ} \mathrm{C}$ with $80 \%$ relative humidity, and $16 \mathrm{~h}$ of light. Three leaf discs per sample were harvested, using a cork borer. Bacteria were extracted from leaf samples by mechanical disruption with steel beads in $10 \mathrm{mM} \mathrm{MgCl}_{2}$. Serial dilutions were spotted on $\mathrm{KB}$ supplemented with $50 \mu \mathrm{g}$ of rifampicin per milliliter. Spots containing $>5$ and $<30$ colonies were used to quantify the number of CFUs per centimeter of leaf tissue.

\section{Tomato syringe-infiltration assay.}

Five- to six-week-old plants were used for syringe-infiltration assays and were acclimatized on the lab bench 1 day prior to infiltration. Bacteria were grown as described above, and were adjusted to a final concentration of $1 \times 10^{4}$ to $5 \times 10^{4} \mathrm{CFU} / \mathrm{ml}$ in $10 \mathrm{mM} \mathrm{MgCl}$. Broad, well-developed leaves were syringeinfiltrated with bacterial suspensions and were maintained under the conditions described above. To enumerate bacterial growth, three leaf discs per spot were harvested, ground, diluted, and spotted as described above.

\section{HR assay.}

Four- to five-week-old Nicotiana tabacum cv. Xanthi or Nicotiana benthamiana were used for the HR assay. P. syringae strains were grown on $\mathrm{KB}$ agar with appropriate antibiotics at $28^{\circ} \mathrm{C}$ for 2 days. The bacteria were resuspended in 100 to $200 \mu \mathrm{l}$ of liquid $\mathrm{KB}$, were spread onto a fresh plate, and were grown for an additional $24 \mathrm{~h}$. Cells were harvested from the plate and were resuspended in $10 \mathrm{mM} \mathrm{MgCl}$. The OD of the cultures was adjusted to an $\mathrm{OD}_{600}$ of 0.2 (approximately $2 \times 10^{8}$ $\mathrm{CFU} / \mathrm{ml}$ ). Serial 10 -fold dilutions were made in $10 \mathrm{mM} \mathrm{MgCl}_{2}$. Cells corresponding to an $\mathrm{OD}_{600}$ of $0.2,0.02$, or 0.002 were used to syringe-infiltrate $N$. benthamiana and tobacco leaves. Plants were left on the laboratory bench to allow for the development of HR.

\section{Translocation assay.}

The plasmid pCPP5388, containing the T3SS translocation reporter adenylate cyclase (Cya) gene fused to the effector AvrPto (Lam et al. 2014; Oh et al. 2007), was transformed into the $\Delta c r c$ strain. The T3SS strain CUCPB5113 was used as a negative control. Translocation assays were performed as described by Lam et al. (2014).

\section{Overlapping cell-death assay for PTI.}

The assay was performed as described (Chakravarthy et al. 2009). Briefly, WT P. fluorescens or $P$. fluorescens $\Delta$ fliC adjusted to an $\mathrm{OD}_{600}=0.5$ (approximately $5 \times 10^{8} \mathrm{CFU} / \mathrm{ml}$ ) was used to induce PTI and was challenged $7 \mathrm{~h}$ later with WT DC3000 or $\Delta c r c$ adjusted to an $\mathrm{OD}_{600}=0.02$ (approximately $2 \times 10^{7} \mathrm{CFU} / \mathrm{ml}$ ). Plants were kept on the lab bench and were scored for the breakdown of PTI in the overlapping area of infiltration.

\section{RNA isolation and qPCR.}

RNA for bacterial virulence genes. Overnight cultures of WT DC3000 or $\Delta c r c$ were grown from fresh KB plates in NB or MG medium or MG in which the mannitol was substituted with succinate or fructose at a final concentration of $1 \%$ (wt/vol). All MG-based media used to grow cells for bacterial qPCR contained $50 \mu \mathrm{M} \mathrm{FeSO}_{4}$, to induce expression of T3SS (Bronstein et al. 2008). The $\mathrm{OD}_{600}$ of the overnight cultures was measured 
and was adjusted to a final of $\mathrm{OD}_{600}=0.1$, in the same medium as the corresponding primary overnight culture. The secondary cultures were in a final volume of $10 \mathrm{ml}$ in $125-\mathrm{ml}$ flasks. They were grown for $7 \mathrm{~h}(\mathrm{NB})$ or $24 \mathrm{~h}$ (mannitol-, succinate-, or fructose-containing media). Aliquots $(1 \mathrm{ml})$ were used to harvest cells, and cell pellets were frozen at $-80^{\circ} \mathrm{C}$. Total RNA was isolated from the frozen cells, using the Quick-RNA miniprep kit (Zymo Research), following manufacturer's instructions.

$R N A$ for plant PTI marker genes. Five-week-old N. benthamiana plants were syringe-infiltrated on well-expanded leaves with bacterial suspensions of DC3000 or the $\Delta c r c$ mutant $\left(\mathrm{OD}_{600}=\right.$ 0.2 ) or $10 \mathrm{mM} \mathrm{MgCl}$. Leaf tissue (six to eight 1-cm leaf discs) was harvested and was flash-frozen $3 \mathrm{~h}$ after syringe-infiltration. Total RNA was isolated, using the RNeasy plant mini kit (Qiagen) (Nguyen et al. 2010).

$q P C R$. Isolated RNA was treated with DNAse (Ambion) to remove residual DNA. RNA was then cleaned using the RNA Clean-up and concentrate kit (Zymo Research). Absence of DNA was confirmed by performing control reactions with primers to the bacterial gene gyrA (PSPTO_1745) or plant gene ATPase (Nguyen et al. 2010). Extracted bacterial and plant RNA was synthesized into cDNA, using the qScript cDNA Supermix (Quanta Biosciences), and qPCR was performed using Bio-Rad SSoAdvanced universal SYBR green supermix (Bio-Rad). For bacterial gene expression, the qPCR was performed in 384-well plates on a ViiA 7 real-time PCR system (Cornell Core Facility). For evaluating plant gene expression, qPCR was performed using 96-well plates on an iQ5 multicolor real-time detection system (BioRad). All primer pairs were found to yield unique products, using the dissociation protocol (data not shown). Gene expression fold change was calculated using the cycle threshold $\left(\Delta \Delta \mathrm{C}_{\mathrm{t}}\right)$ method. For bacterial qPCR, the reference gene used was gyrA (PSPTO_1745). The ATPase gene served as the reference gene for plant qPCR (Nguyen et al. 2010). Primers used for bacterial qPCR are listed in Supplementary Table S1. Primers used for plant qPCR were as previously published (Nguyen et al. 2010).

Extracted bacterial and plant RNA was synthesized into cDNA, using the qScript cDNA supermix (Quanta Biosciences), and qPCR was performed using Bio-Rad SSoAdvanced universal SYBR green supermix (Bio-Rad). For bacterial gene expression, the PCR was performed in 384-well plates on a ViiA 7 real-time PCR system (Cornell Core Facility). For evaluating gene expression in infiltrated $N$. benthamiana plants, qPCR was performed using 96-well plates on a iQ5 multicolor real-time detection system (BioRad). All primer pairs have been previously shown to yield unique products, using the dissociation protocol (data not shown). Gene-expression fold change was calculated using the $\Delta \Delta \mathrm{C}_{\mathrm{t}}$ method. $\mathrm{C}_{\mathrm{t}}$ values of each gene tested were normalized to the $C_{t}$ values of the housekeeping gene gapl (PSPTO_1287).

\section{Assay for ROS.}

The method for ROS measurement was adapted from previous studies (Smith and Heese 2014; Wei et al. 2013). Leaf discs of four-week-old $N$. benthamiana were excised and placed individually into wells of a 96-well plate, containing $100 \mu \mathrm{l}$ of distilled $\mathrm{H}_{2} \mathrm{O}$, and were allowed to incubate for $20 \mathrm{~h}$ for wound recovery. Bacterial suspensions made from fresh plates were spread onto $\mathrm{KB}$ agar plates and were incubated at $28^{\circ} \mathrm{C}$ for $24 \mathrm{~h}$. Bacteria were harvested and $\mathrm{OD}_{600}$ was measured. Distilled $\mathrm{H}_{2} \mathrm{O}$ was removed from the multiwell plates and the following mixture was added: $100 \mu \mathrm{l}$ of $0.5 \mathrm{mM} \mathrm{L-012}$ (Wako) in $10 \mathrm{mM}$ morpholinepropanesulfonic acid-KOH buffer ( $\mathrm{pH} 7.4$ ), containing the bacterial suspension at a final $\mathrm{OD}_{600}$ of 0.1 (approximately $1 \times 10^{8} \mathrm{CFU} \mathrm{ml}^{-1}$ ). Controls included wells with no bacteria. The intensity of ROS production was determined by monitoring the chemiluminescence between 0 and 120 min, using a Biotek Synergy 2 microplate reader. Each experiment was done three independent times with similar results.

\section{ACKNOWLEDGMENTS}

We thank A. Rossi for preliminary swarming experiments, J. Wilson for construction of the $c b r A$ deletion strain, and M. Fishman for helpful discussions. The United States Department of Agriculture (USDA) is an equal opportunity provider and employer. Mention of trade names or commercial products in this publication is solely for the purposes of providing specific information and does not imply recommendation or endorsement by the USDA.

\section{LITERATURE CITED}

Alfano, J. R., and Collmer, A. 2004. Type III secretion system effector proteins: Double agents in bacterial disease and plant defense. Annu. Rev. Phytopathol. 42:385-414.

Alfano, J. R., Klm, H. S., Delaney, T. P., and Collmer, A. 1997. Evidence that the Pseudomonas syringae pv. syringae hrp-linked hrmA gene encodes an Avr-like protein that acts in an hrp-dependent manner within tobacco cells. Mol. Plant-Microbe Interact. 10:580-588.

Anderson, J. C., Wan, Y., Kim, Y. M., Pasa-Tolic, L., Metz, T. O., and Peck, S. C. 2014. Decreased abundance of type III secretion system-inducing signals in Arabidopsis mkpl enhances resistance against Pseudomonas syringae. Proc. Natl. Acad. Sci. U.S.A. 111:6846-6851.

Arrebola, E., Carrión, V. J., Gutiérrez-Barranquero, J. A., Pérez-García, A., Rodríguez-Palenzuela, P., Cazorla, F. M., and de Vicente, A. 2015. Cellulose production in Pseudomonas syringae pv. syringae: A compromise between epiphytic and pathogenic lifestyles. FEMS Microbiol. Ecol. 91: fiv071.

Berti, A. D., Greve, N. J., Christensen, Q. H., and Thomas, M. G. 2007. Identification of a biosynthetic gene cluster and the six associated lipopeptides involved in swarming motility of Pseudomonas syringae pv. tomato DC3000. J. Bacteriol. 189:6312-6323.

Boureau, T., Routtu, J., Roine, E., Taira, S., and Romantschuk, M. 2002. Localization of hrpA-induced Pseudomonas syringae pv. tomato DC3000 in infected tomato leaves. Mol. Plant Pathol. 3:451-460.

Bronstein, P. A., Filiatrault, M. J., Myers, C. R., Rutzke, M., Schneider, D. J., and Cartinhour, S. W. 2008. Global transcriptional responses of Pseudomonas syringae DC3000 to changes in iron bioavailability in vitro. BMC Microbiol. 8:209.

Browne, P., Barret, M., O'Gara, F., and Morrissey, J. P. 2010. Computational prediction of the Crc regulon identifies genus-wide and species-specific targets of catabolite repression control in Pseudomonas bacteria. BMC Microbiol. 10:300.

Buell, C. R., Joardar, V., Lindeberg, M., Selengut, J., Paulsen, I. T., Gwinn, M. L., Dodson, R. J., Deboy, R. T., Durkin, A. S., Kolonay, J. F., Madupu, R., Daugherty, S., Brinkac, L., Beanan, M. J., Haft, D. H., Nelson, W. C., Davidsen, T., Zafar, N., Zhou, L., Liu, J., Yuan, Q., Khouri, H., Fedorova, N., Tran, B., Russell, D., Berry, K., Utterback, T., Van Aken, S. E., Feldblyum, T. V., D’Ascenzo, M., Deng, W. L., Ramos, A. R., Alfano, J. R., Cartinhour, S., Chatterjee, A. K., Delaney, T. P., Lazarowitz, S. G., Martin, G. B., Schneider, D. J., Tang, X., Bender, C. L., White, O., Fraser, C. M., and Collmer, A. 2003. The complete genome sequence of the Arabidopsis and tomato pathogen Pseudomonas syringae pv. tomato DC3000. Proc. Natl. Acad. Sci. U.S.A. 100:10181-10186.

Burch, A. Y., Shimada, B. K., Browne, P. J., and Lindow, S. E. 2010. Novel high-throughput detection method to assess bacterial surfactant production. Appl. Environ. Microbiol. 76:5363-5372.

Burch, A. Y., Shimada, B. K., Mullin, S. W., Dunlap, C. A., Bowman, M. J., and Lindow, S. E. 2012. Pseudomonas syringae coordinates production of a motility-enabling surfactant with flagellar assembly. J. Bacteriol. 194:1287-1298.

Caiazza, N. C., Merritt, J. H., Brothers, K. M., and O’Toole, G. A. 2007. Inverse regulation of biofilm formation and swarming motility by Pseudomonas aeruginosa PA14. J. Bacteriol. 189:3603-3612.

Chakravarthy, S., Velásquez, A. C., and Martin, G. B. 2009. Assay for pathogen-associated molecular pattern (PAMP)-triggered immunity (PTI) in plants. J. Vis. Exp. doi:10.3791/1442. Published online.

Coll, N. S., Epple, P., and Dangl, J. L. 2011. Programmed cell death in the plant immune system. Cell Death Differ. 18:1247-1256.

Cuppels, D. A. 1986. Generation and characterization of Tn5 insertion mutations in Pseudomonas syringae pv. tomato. Appl. Environ. Microbiol. 51:323-327. 
Déziel, E., Lépine, F., Milot, S., and Villemur, R. 2003. rhlA is required for the production of a novel biosurfactant promoting swarming motility in Pseudomonas aeruginosa: 3-(3-hydroxyalkanoyloxy)alkanoic acids (HAAs), the precursors of rhamnolipids. Microbiology 149:2005-2013.

Dong, Y. H., Zhang, X. F., and Zhang, L. H. 2013. The global regulator Crc plays a multifaceted role in modulation of type III secretion system in Pseudomonas aeruginosa. MicrobiologyOpen 2:161-172.

Engl, C., Waite, C. J., McKenna, J. F., Bennett, M. H., Hamann, T., and Buck, M. 2014. Chp8, a diguanylate cyclase from Pseudomonas syringae pv. Tomato DC3000, suppresses the pathogen-associated molecular pattern flagellin, increases extracellular polysaccharides, and promotes plant immune evasion. MBio 5:e01168-e14.

Filiatrault, M. J., Stodghill, P. V., Wilson, J., Butcher, B. G., Chen, H., Myers, C. R., and Cartinhour, S. W. 2013. CrcZ and CrcX regulate carbon source utilization in Pseudomonas syringae pathovar tomato strain DC3000. RNA Biol. 10:245-255.

Görke, B., and Stülke, J. 2008. Carbon catabolite repression in bacteria: Many ways to make the most out of nutrients. Nat. Rev. Microbiol. 6: 613-624.

Greenberg, J. T., and Yao, N. 2004. The role and regulation of programmed cell death in plant-pathogen interactions. Cell. Microbiol. 6:201-211.

Haefele, D. M., and Lindow, S. E. 1987. Flagellar motility confers epiphytic fitness advantages upon Pseudomonas syringae. Appl. Environ. Microbiol. 53:2528-2533.

Hanahan, D. 1983. Studies on transformation of Escherichia coli with plasmids. J. Mol. Biol. 166:557-580.

Hsiao, Y. M., Liu, Y. F., Fang, M. C., and Song, W. L. 2011. XCC2731, a GGDEF domain protein in Xanthomonas campestris, is involved in bacterial attachment and is positively regulated by Clp. Microbiol. Res. 166:548-565.

Ichinose, Y., Taguchi, F., and Mukaihara, T. 2013. Pathogenicity and virulence factors of Pseudomonas syringae. J. Gen. Plant Pathol. 79: 285-296.

Katagiri, F., Thilmony, R., and He, S. Y. 2002. The Arabidopsis thaliana-Pseudomonas syringae interaction. Arabidopsis Book 1:e0039.

Keane, P. J., Kerr, A., and New, P. B. 1970. Crown gall of stone fruit. 2. Identification and nomenclature of agrobacterium isolates. Aust. J. Biol. Sci. 23:585.

King, E. O., Ward, M. K., and Raney, D. E. 1954. Two simple media for the demonstration of pyocyanin and fluorescin. J. Lab. Clin. Med. 44: 301-307.

Lam, H. N., Chakravarthy, S., Wei, H. L., BuiNguyen, H., Stodghill, P. V., Collmer, A., Swingle, B. M., and Cartinhour, S. W. 2014. Global analysis of the HrpL regulon in the plant pathogen Pseudomonas syringae pv. tomato DC3000 reveals new regulon members with diverse functions. PLoS One 9:e106115.

Lamb, C., and Dixon, R. A. 1997. THE OXIDATIVE BURST IN PLANT DISEASE RESISTANCE. Annu. Rev. Plant Physiol. Plant Mol. Biol. 48: 251-275.

Laue, H., Schenk, A., Li, H., Lambertsen, L., Neu, T. R., Molin, S., and Ullrich, M. S. 2006. Contribution of alginate and levan production to biofilm formation by Pseudomonas syringae. Microbiology 152: 2909-2918.

Linares, J. F., Moreno, R., Fajardo, A., Martínez-Solano, L., Escalante, R., Rojo, F., and Martínez, J. L. 2010. The global regulator Crc modulates metabolism, susceptibility to antibiotics and virulence in Pseudomonas aeruginosa. Environ. Microbiol. 12:3196-3212.

Mellgren, E. M., Kloek, A. P., and Kunkel, B. N. 2009. Mqo, a tricarboxylic acid cycle enzyme, is required for virulence of Pseudomonas syringae pv. tomato strain DC3000 on Arabidopsis thaliana. J. Bacteriol. 191: 3132-3141.

Milojevic, T., Grishkovskaya, I., Sonnleitner, E., Djinovic-Carugo, K., and Bläsi, U. 2013. The Pseudomonas aeruginosa catabolite repression control protein $\mathrm{Crc}$ is devoid of RNA binding activity. PLoS One 8: e64609.

Monaghan, J., and Zipfel, C. 2012. Plant pattern recognition receptor complexes at the plasma membrane. Curr. Opin. Plant Biol. 15:349-357.

Morales, G., Linares, J. F., Beloso, A., Albar, J. P., Martínez, J. L., and Rojo, F. 2004. The Pseudomonas putida Crc global regulator controls the expression of genes from several chromosomal catabolic pathways for aromatic compounds. J. Bacteriol. 186:1337-1344.

Moreno, R., Fonseca, P., and Rojo, F. 2012. Two small RNAs, CrcY and $\mathrm{CrcZ}$, act in concert to sequester the $\mathrm{Crc}$ global regulator in Pseudomonas putida, modulating catabolite repression. Mol. Microbiol. 83:24-40.

Moreno, R., Hernández-Arranz, S., La Rosa, R., Yuste, L., Madhushani, A., Shingler, V., and Rojo, F. 2015. The Crc and Hfq proteins of Pseudomonas putida cooperate in catabolite repression and formation of ribonucleic acid complexes with specific target motifs. Environ. Microbiol. 17:105-118

Morris, V. L., Jackson, D. P., Grattan, M., Ainsworth, T., and Cuppels, D. A. 1995. Isolation and sequence analysis of the Pseudomonas syringae pv. tomato gene encoding a 2,3-diphosphoglycerate-independent phosphoglyceromutase. J. Bacteriol. 177:1727-1733.

Nguyen, H. P., Chakravarthy, S., Velásquez, A. C., McLane, H. L., Zeng, L., Nakayashiki, H., Park, D. H., Collmer, A., and Martin, G. B. 2010. Methods to study PAMP-triggered immunity using tomato and Nicotiana benthamiana. Mol. Plant-Microbe Interact. 23:991-999.

Nicaise, V., Roux, M., and Zipfel, C. 2009. Recent advances in PAMPtriggered immunity against bacteria: Pattern recognition receptors watch over and raise the alarm. Plant Physiol. 150:1638-1647.

Nogales, J., P. Vargas, G. A. Farias, A. Olmedilla, J. Sanjuan, and M. T. Gallegos. 2015. FleQ coordinates flagella-dependent and -independent motilities in Pseudomonas syringae pv. tomato DC3000. Appl Environ Microbiol. 81:7533-7545.

O’Toole, G. A. 2011. Microtiter dish biofilm formation assay. J. Vis. Exp. doi:10.3791/2437. Published online.

O’Toole, G. A., Gibbs, K. A., Hager, P. W., Phibbs, P. V., Jr., and Kolter, R. 2000. The global carbon metabolism regulator $\mathrm{Crc}$ is a component of a signal transduction pathway required for biofilm development by Pseudomonas aeruginosa. J. Bacteriol. 182:425-431.

Oh, H. S., Kvitko, B. H., Morello, J. E., and Collmer, A. 2007. Pseudomonas syringae lytic transglycosylases coregulated with the type III secretion system contribute to the translocation of effector proteins into plant cells. J. Bacteriol. 189:8277-8289.

Oh, H. S., Park, D. H., and Collmer, A. 2010. Components of the Pseudomonas syringae type III secretion system can suppress and may elicit plant innate immunity. Mol. Plant-Microbe Interact. 23: 727-739.

Park, D. H., Mirabella, R., Bronstein, P. A., Preston, G. M., Haring, M. A., Lim, C. K., Collmer, A., and Schuurink, R. C. 2010. Mutations in $\gamma$-aminobutyric acid (GABA) transaminase genes in plants or Pseudomonas syringae reduce bacterial virulence. Plant J. 64:318-330.

Park, S. H., Butcher, B. G., Anderson, Z., Pellegrini, N., Bao, Z., D’Amico, K., and Filiatrault, M. J. 2013. Analysis of the small RNA P16/RgsA in the plant pathogen Pseudomonas syringae pv. tomato strain DC3000. Microbiology 159:296-306.

Pauwelyn, E., Huang, C. J., Ongena, M., Leclère, V., Jacques, P., Bleyaert, P., Budzikiewicz, H., Schäfer, M., and Höfte, M. 2013. New linear lipopeptides produced by Pseudomonas cichorii SF1-54 are involved in virulence, swarming motility, and biofilm formation. Mol. PlantMicrobe Interact. 26:585-598.

Pérez-Mendoza, D., Aragón, I. M., Prada-Ramírez, H. A., RomeroJiménez, L., Ramos, C., Gallegos, M. T., and Sanjuán, J. 2014. Responses to elevated c-di-GMP levels in mutualistic and pathogenic plant-interacting bacteria. PLoS One 9:e91645.

Pfeilmeier, S., Saur, I. M., Rathjen, J. P., Zipfel, C., and Malone, J. G. 2016. High levels of cyclic-di-GMP in plant-associated Pseudomonas correlate with evasion of plant immunity. Mol. Plant Pathol. 17:521-531.

Pombo, M. A., Zheng, Y., Fernandez-Pozo, N., Dunham, D. M., Fei, Z., and Martin, G. B. 2014. Transcriptomic analysis reveals tomato genes whose expression is induced specifically during effector-triggered immunity and identifies the Epk1 protein kinase which is required for the host response to three bacterial effector proteins. Genome Biol. 15: 492.

Poncet, S., Milohanic, E., Mazé, A., Nait Abdallah, J., Aké, F., Larribe, M., Deghmane, A. E., Taha, M. K., Dozot, M., De Bolle, X., Letesson, J. J., and Deutscher, J. 2009. Correlations between carbon metabolism and virulence in bacteria. Contrib. Microbiol. 16:88-102.

Preston, G., Huang, H. C., He, S. Y., and Collmer, A. 1995. The HrpZ proteins of Pseudomonas syringae pvs. syringae, glycinea, and tomato are encoded by an operon containing Yersinia ysc homologs and elicit the hypersensitive response in tomato but not soybean. Mol. Plant-Microbe Interact. 8:717-732.

Preston, G. M. 2000. Pseudomonas syringae pv. tomato: The right pathogen, of the right plant, at the right time. Mol. Plant Pathol. 1:263-275.

Records, A. R., and Gross, D. C. 2010. Sensor kinases RetS and LadS regulate Pseudomonas syringae type VI secretion and virulence factors. J. Bacteriol. 192:3584-3596.

Rico, A., and Preston, G. M. 2008. Pseudomonas syringae pv. tomato DC3000 uses constitutive and apoplast-induced nutrient assimilation pathways to catabolize nutrients that are abundant in the tomato apoplast. Mol. Plant-Microbe Interact. 21:269-282.

Rojo, F. 2010. Carbon catabolite repression in Pseudomonas: Optimizing metabolic versatility and interactions with the environment. FEMS Microbiol. Rev. 34:658-684. 
Römling, U., Galperin, M. Y., and Gomelsky, M. 2013. Cyclic di-GMP: The first 25 years of a universal bacterial second messenger. Microbiol. Mol. Biol. Rev. 77:1-52.

Rosli, H. G., Zheng, Y., Pombo, M. A., Zhong, S., Bombarely, A., Fei, Z., Collmer, A., and Martin, G. B. 2013. Transcriptomics-based screen for genes induced by flagellin and repressed by pathogen effectors identifies a cell wall-associated kinase involved in plant immunity. Genome Biol. 14:R139.

Schäfer, A., Tauch, A., Jäger, W., Kalinowski, J., Thierbach, G., and Pühler, A. 1994. Small mobilizable multi-purpose cloning vectors derived from the Escherichia coli plasmids pK18 and pK19: Selection of defined deletions in the chromosome of Corynebacterium glutamicum. Gene 145:69-73.

Schechter, L. M., Roberts, K. A., Jamir, Y., Alfano, J. R., and Collmer, A. 2004. Pseudomonas syringae type III secretion system targeting signals and novel effectors studied with a Cya translocation reporter. J. Bacteriol. 186:543-555.

Schurr, M. J. 2013. Which bacterial biofilm exopolysaccharide is preferred, Psl or alginate? J. Bacteriol. 195:1623-1626.

Schweizer, H. P. 1991. Escherichia-Pseudomonas shuttle vectors derived from pUC18/19. Gene 97:109-112.

Smith, J. M., and Heese, A. 2014. Rapid bioassay to measure early reactive oxygen species production in Arabidopsis leave tissue in response to living Pseudomonas syringae. Plant Methods 10:6.

Sonnleitner, E., Abdou, L., and Haas, D. 2009. Small RNA as global regulator of carbon catabolite repression in Pseudomonas aeruginosa. Proc. Natl. Acad. Sci. U.S.A. 106:21866-21871.

Sonnleitner, E., and Bläsi, U. 2014. Regulation of Hfq by the RNA CrcZ in Pseudomonas aeruginosa carbon catabolite repression. PLoS Genet. 10:e1004440.

Sreedharan, A., Penaloza-Vazquez, A., Kunkel, B. N., and Bender, C. L. 2006. CorR regulates multiple components of virulence in Pseudomonas syringae pv. tomato DC3000. Mol. Plant-Microbe Interact. 19:768-779.

Ude, S., Arnold, D. L., Moon, C. D., Timms-Wilson, T., and Spiers, A. J. 2006. Biofilm formation and cellulose expression among diverse environmental Pseudomonas isolates. Environ. Microbiol. 8:1997-2011.
Valentini, M., and Filloux, A. 2016. Biofilms and cyclic di-GMP (c-diGMP) signaling: Lessons from Pseudomonas aeruginosa and Other Bacteria. J. Biol. Chem. 291:12547-12555.

Wang, S., Yu, S., Zhang, Z., Wei, Q., Yan, L., Ai, G., Liu, H., and Ma, L. Z. 2014. Coordination of swarming motility, biosurfactant synthesis, and biofilm matrix exopolysaccharide production in Pseudomonas aeruginosa. Appl. Environ. Microbiol. 80:6724-6732.

Wei, C. F., Kvitko, B. H., Shimizu, R., Crabill, E., Alfano, J. R., Lin, N. C., Martin, G. B., Huang, H. C., and Collmer, A. 2007. A Pseudomonas syringae pv. tomato DC3000 mutant lacking the type III effector HopQ1-1 is able to cause disease in the model plant Nicotiana benthamiana. Plant J. 51:32-46.

Wei, H. L., Chakravarthy, S., Worley, J. N., and Collmer, A. 2013. Consequences of flagellin export through the type III secretion system of Pseudomonas syringae reveal a major difference in the innate immune systems of mammals and the model plant Nicotiana benthamiana. Cell. Microbiol. 15:601-618.

Wu, S., Shan, L., and He, P. 2014. Microbial signature-triggered plant defense responses and early signaling mechanisms. Plant Sci. 228: 118-126.

Xin, X. F., and He, S. Y. 2013. Pseudomonas syringae pv. tomato DC3000: A model pathogen for probing disease susceptibility and hormone signaling in plants. Annu. Rev. Phytopathol. 51:473-498.

Yeung, A. T., Bains, M., and Hancock, R. E. 2011. The sensor kinase CbrA is a global regulator that modulates metabolism, virulence, and antibiotic resistance in Pseudomonas aeruginosa. J. Bacteriol. 193:918-931.

Yu, J., Peñaloza-Vázquez, A., Chakrabarty, A. M., and Bender, C. L. 1999. Involvement of the exopolysaccharide alginate in the virulence and epiphytic fitness of Pseudomonas syringae pv. syringae. Mol. Microbiol. 33:712-720.

Yu, X., Lund, S. P., Scott, R. A., Greenwald, J. W., Records, A. H., Nettleton, D., Lindow, S. E., Gross, D. C., and Beattie, G. A. 2013. Transcriptional responses of Pseudomonas syringae to growth in epiphytic versus apoplastic leaf sites. Proc. Natl. Acad. Sci. U.S.A. 110:E425-E434. 